\title{
Assessing pollution trends in the Guadalquivir River estuary using $\mathrm{N}$-way analysis
}

\author{
J. A. López-López ${ }^{1}$, C. Mendiguchía, M. García-Vargas and C. Moreno \\ ${ }^{1}$ University of Cádiz. Department of Analytical Chemistry. Faculty of Marine and Environmental Sciences. República \\ Saharaui s/n PC: 11510, Puerto Real (Spain). e-mail: joseantonio.lopezlopez@uca.es
}

\begin{abstract}
Human activities have contributed to a deployment of environmental quality. In the last decades the problem of water preservation has gained increasing attention, and new policies have been developed for water resources remediation. Statistical techniques for data treatment are based on the organization of data in a bi-dimensional array; thus, some shades on the trend of the distribution tend to be ignored. Multiway techniques, where data are gathered in $\mathrm{n}$ directions, allow the analysis of the results through different directions at the same time. In particular, for 3MPCA a principal components analysis is conducted using three modes and a "core" matrix that allows assessing their interactions. The Guadalquivir River estuary has been used as a model system for the application of 3MPCA in the study of long term evolution of pollutants. Nutrients and heavy metals ultra-traces level have been used to characterize the estuary. The 3MPCA was used to assess the relationships within chemical variables, sampling stations and sampling campaigns.
\end{abstract}

Keywords: Heavy metals, 3MPCA, anthropogenic pollution, urban sewage

\section{Introduction}

Alongside History, human activities have contributed to a deployment of environmental quality. Moreover, since the Industrial Revolution, pollution inputs have been considered as responsible of water resources degradation. Then, in the last decades the problem of water preservation has gained increasing attention, and new policies have been developed for remediating water resources.

Application of statistical analysis is essential to analyze environmental data and to identify trends of pollutants over space and time. Usually applied techniques for data treatment are based on the organization of data in a bi-dimensional array; thus, the average data of a series of sampling campaigns are used, and some shades on the trend of the distribution tend to be ignored. This fact supports the use of multi-way techniques [1], where data are gathered in $\mathrm{n}$ directions called modes, allowing the analysis of the results through different directions at the same time. In particular, for three modes principal components analysis (3MPCA), a principal components analysis is conducted using three modes and the interactions are gathered in a matrix called core.

\section{Materials and Methods}

Study site

The Guadalquivir River is representative of the effects of human activities on water courses. It is the main source of water in the South-Atlantic Spanish basin, and its estuary coincides also with its navigable part. The estuary drains through the city of Seville in its upper part, which has been previously characterized as a source of urban and industrial pollution. In this area, different waste water treatment plants can be found; in addition, some of them began operating during the period of study, so this is a good indicator of the impact of policies applied on environmental protection. Down waters, the estuary crosses an agriculture area, where cereals appear as mean crop. Finally, the river crosses beside the Doñana National Park until its mouth [2].

\section{Statistical analysis}

Taking into account the characteristics of this estuary, 3MPCA was applied to study long term evolution of pollutants from human activities in the period 2001-2008. In particular, the trend of $\mathrm{pH}$, dissolved oxygen, total 

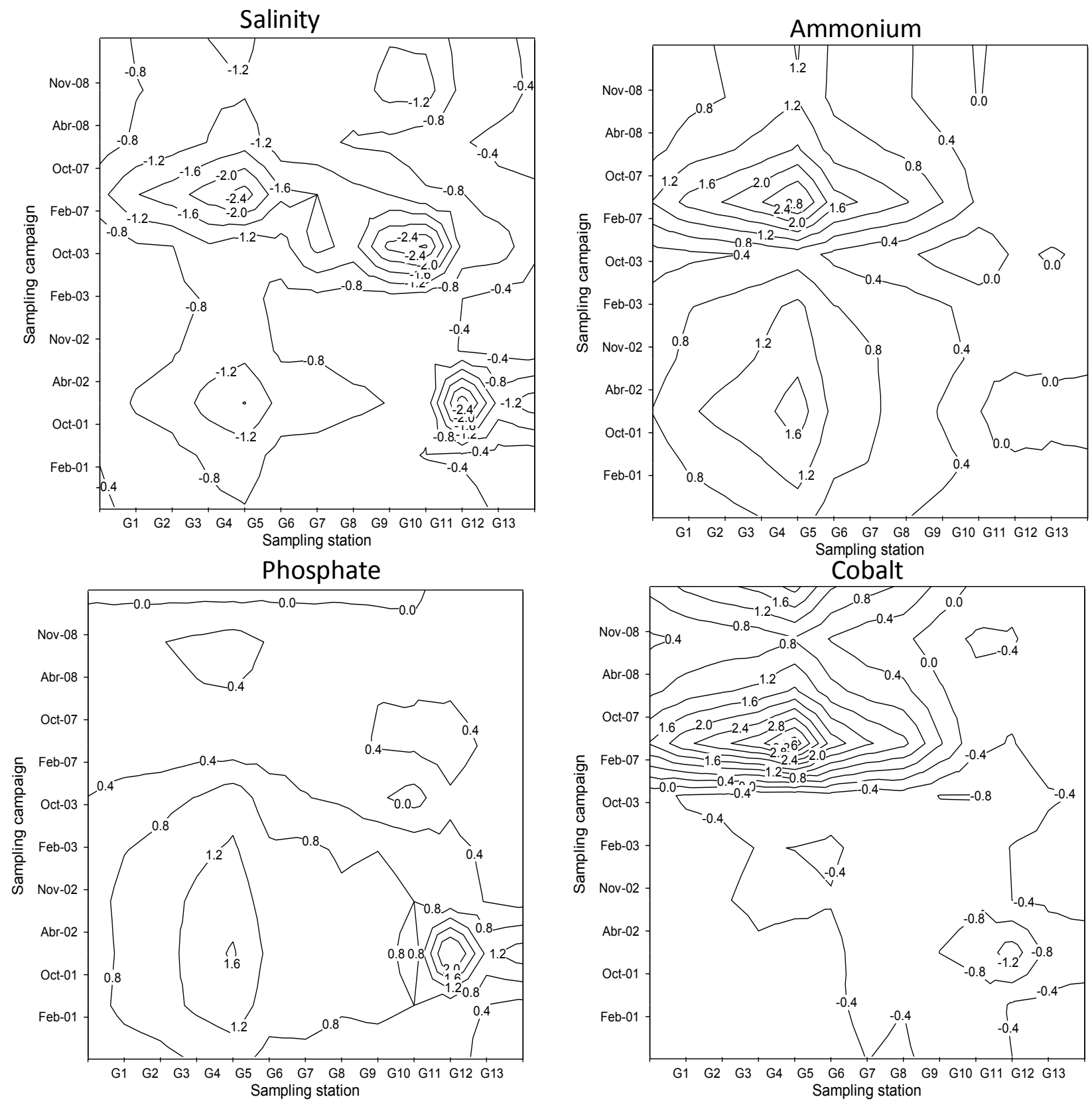

Fig. 2 Iso-score plots for conductivity, $\mathrm{NH}_{4}{ }^{+}, \mathrm{PO}_{4}{ }^{3-}$ and $\mathrm{Co}$

suspended solids, $\mathrm{PO}_{4}{ }^{3-}, \mathrm{NO}_{3}{ }^{-}, \mathrm{NO}_{2}{ }^{-}, \mathrm{NH}_{4}{ }^{+}, \mathrm{Pb}, \mathrm{Ni}, \mathrm{Zn}$, $\mathrm{Cd}, \mathrm{Mn}, \mathrm{Co}$ and $\mathrm{Cu}$. In order to do this, the interactions within sampling sites, chemical variables and sampling campaigns where described using a 3, 4 and 4 components for Mode A, Mode B and Mode C, respectively. The core matrix was employed to identify the interactions within chemical variables, sampling stations and sampling campaigns, and joint plots were used represent the extent of the interactions between variables along time and space. In the case of environmental studies, this gives information about long term evolution of pollutants in a certain body of water, because it considers the interactions of the standard individual values in the three modes: sampling stations (Mode A), chemical variables (Mode B) and sampling campaigns (Mode C) (Fig. 1).

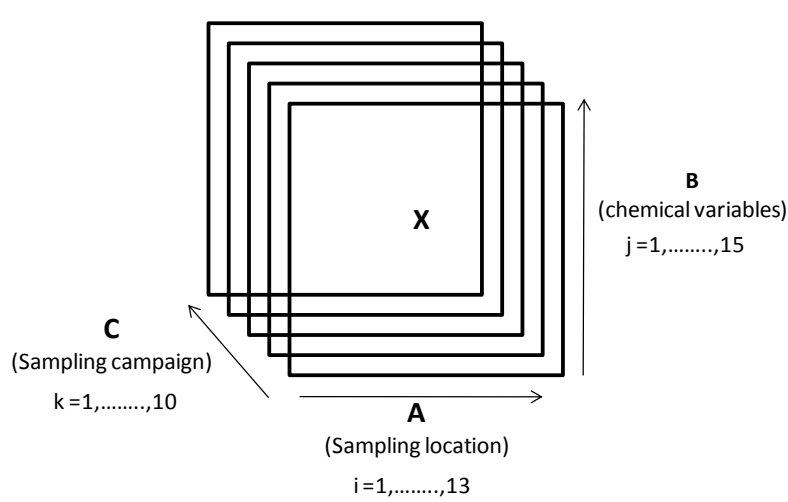

Fig.1 Configuration of the three dimensional array 


\section{Results and Discussion}

Chemical variables were classified by the observed interactions in the core, because it gives an idea of their behavior alongside the river during the studied period. In particular, iso-scores plots were constructed for each variable to identify their evolution during the studied period alongside the length of the estuary. Finally, pollutants were classified by the observed pattern in the iso-scores plots (Fig. 2).

As a result, conductivity, $\mathrm{pH}, \mathrm{DO}, \mathrm{Cd}, \mathrm{Ni}, \mathrm{Zn}$ and $\mathrm{Cu}$, could be included in the same group and their behavior could be considered to be conditioned by the mixture of river and seawater. The evolution of total suspended solids is related with eventual rain events and the opening of a dam on the top of the estuary. $\mathrm{And} \mathrm{NH}_{4}{ }^{+}$, $\mathrm{NO}_{2}^{-}$show an important relationship with sampling campaigns from 2007 in the area of Seville. The influence of $\mathrm{Pb}$ and $\mathrm{PO}_{4}^{3-}$ on the estuary has considerably decreased during the studied period. This fact is supported because the use of leaded fuel was forbidden in 2001 [3] and the European Commission recommended avoiding the use of $\mathrm{PO}_{4}{ }^{3-}$ in detergents [4]. Finally, the evolution of Co from 2007 in the area of Seville has become more important, probably due to its inclusion in new technology devices and medical treatment, in the last years [5].

\section{Conclusion}

Three way analysis of the results allowed understanding the evolution of pollutants alongside the Guadalquivir River estuary in the period 2001-2008. In particular, the behavior of some pollutants as $\mathrm{Pb}, \mathrm{PO}_{4}{ }^{3-}$ and $\mathrm{Co}$, appears as a tracer for the evolution of human activities during the last years.

\section{References}

1. Kiers, H.A.L. and van Mechelen, I. Three-way component analysis: Principles and illustrative application. Psychological methods 2001

2. López-López, J.A.; García-Vargas, M. and Moreno, C. A chemometric approach to the evaluation of atmospheric and fluvial pollutant inputs in aquatic system: The Guadalquivir River estuary as a case study. Environmental Pollution 2011; 159: 1136-1143

3. Directive 98/70/EC of the European Parliament and of the Council of 13 October 1998 relating to the quality of petrol and diesel fuels and amending Council Directive 97/12/EEC. Official Journal (OJ L 350), 28/12/1998

4. Report from the commission to the council and the European Parliament. Pursuant to Article 16 of Regulation (EC) No 648-2004 of the European Parliament and of the Council of 31 March 2004 on detergents, concerning the use of phosphates

5. Mutlu, P.; Baran, Y.; Ural, A.U.; Avcu, F.; Dirican, B.; Beyzadeouglu, M and Gündüz, U. Effect of o-60 ( -radiation) on multidrug-resistan myeloma cells lines. Cell Biology International 2011; 35: 721-725 